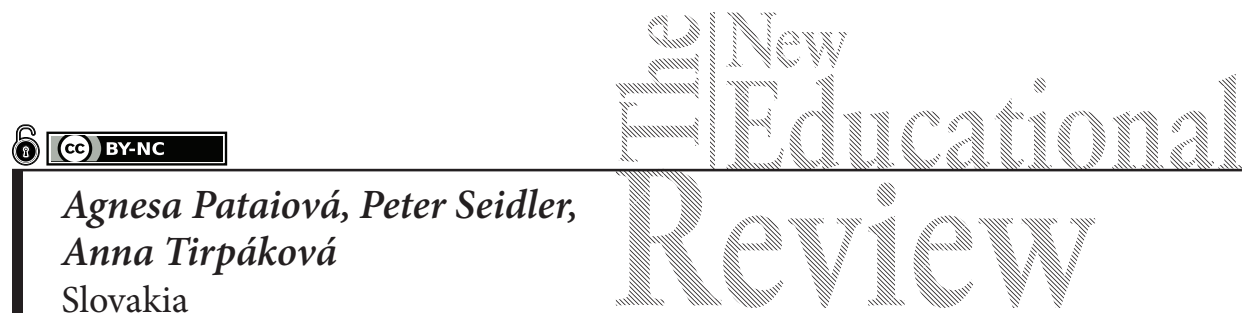

\title{
Verification of the Effectiveness of a New Education and Training Programme for Mentally Disabled Adolescents
}

DOI: 10.15804/tner.2019.55.1.22

\begin{abstract}
The contribution presents a new education and training programme "Stepping into Life with the Right Values," aimed to improve integration of mentally disabled pupils into the system of vocational training centres and thus also society. The goal of the presented programme was not only to create suitable conditions for pupils' harmonious adaptation to the dormitory environment, but also to teach them appropriate orientation in various life situations. Effectiveness of the programme was verified experimentally at selected vocational training centres in Slovakia during the 2015/2016, 2016/2017 and 2017/2018 school years. Our research confirmed that pupils who had gone through the adaptation process using the new programme were statistically significantly better oriented in ordinary life situations at the school dormitory, but also in ordinary life situations outside.
\end{abstract}

Keywords: support and education programme, mental disability, adolescence, integration

\section{Introduction}

Not only in pedagogy, but also in ordinary life, can we observe that adolescent pupils form their own critical opinions. Adolescence is a period when, according to Višňovský et al. (2001), adolescents form moral convictions and develop moral 
characteristics, with school playing a significant part there. In mentally disabled pupils, the process is partly modified. Formation of moral convictions and moral characteristics in such pupils must be facilitated by school - educators - to a much greater extent than in the case of healthy children. Especially educators in the dormitory can, by their influence, personal tact and educational competence, suitably influence their wards in their free time, in particular, pupils coming from socially weaker, incomplete, even dysfunctional families. The duty to improve the situation at least partially, thus, rests on educators in individual school facilities.

The system of adolescents' value orientations represents the highest level of the dispositional hierarchy regulating their behaviour. Individual values cannot be extracted or interpreted in isolation, because their sense depends on what other values (goals, aspirations, interests, etc.) they are interlinked with and how. Finding out individuals' value orientations is important also because they allow for predicting, to some extent, individuals' behaviour in future. The issue has been subject to a lot of research (Hofstede, 2001; Prunner, 2002, 2013; Roccas, Sagiv, Schwartz, Knafo, 2002; Aluja \& García, 2004). However, if considering relationships of values, value structure and personality traits in mentally disabled adolescents, it is necessary to examine in more detail also the extent to which values correspond to other personality traits of the mentally disabled. If there is no consistence with the overall personality structure of the disabled, they may experience dissonance. The biggest mystery is how to find the correct answer to the question: "To what extent do the values and personality traits of the disabled decide on their actions?" The answer to the question has been looked for also by Aluja and Garcia (2004), who arrived at the conclusion that although personality traits and values are individual differences, they are consistent in various situations and at various times. The issue has been dealt with also by Roccas, Sagiv, Schwartz, Knafo (2002), in their research analysing relationships between the BIG FIVE factors and personal values. Another author who has studied relationships between value references, structures and personality traits is Prunner (2002). In his research, Prunner has used several research methods such as questionnaires to find out interpersonal values, social frustration, questionnaires measuring socio-pathological reactions and mental state questionnaires. On the basis of his findings, he states that the value structure may not always fully match a person's personality profile.

In 2014, the Slovak government approved a new conception (applicable until 2020) for work with mentally disabled youth ${ }^{1}$. The aim of the document is, among other things, that since vocational training centres have immense "power" in

1 https://www.minedu.sk/data/files/5133_p4_msvvas.pdf 
their hands, the right way should be found, or looked for, how to create suitable conditions for integrated and inclusive education of children and youth, while preserving and supporting special education where necessary, not only for mental disability, but also for multiple serious health disabilities. The proposed Strategy of the Slovak Republic for Youth for the Years 2014-2020 is a strategic document creating a new framework for the support and development of young people up to 30 years of age and its fulfilment is participated by the inter-departmental work group of national youth policy. Individual strategies are based on themes of the EU Youth Strategy. Unambiguous priorities of the document are youth education and training, supplemented by another area, i.e., direct work with youth.

In accordance with the new conception approved by the government of the Slovak Republic for the work with mentally disabled youth ${ }^{2}$ we developed a new education and training programme "Stepping into Life with the Right Values" for mentally disabled adolescents in the dormitories of vocational training centres.

\section{$\underline{\text { Research Methodology }}$}

\section{Intensive education and training programme "Stepping into Life with the Right Values"}

The programme was developed and applied in cooperation with a psychologist and consisted of three modules. Module 1 was for the $1^{\text {st }}$ grade of vocational training centre for the period from September to June. Module 2 was implemented during the whole school year and Module 3 was applied in the 3rd grade and ended in December. Upon termination of the programme, each pupil took part in the closing act, consisting in practical performance of a selected model situation in front of their own group or reading their own essay aimed at assessment of the benefit for the particular pupil. The programme consisted of 76 lessons, out of it 26 lessons of theory and 50 lessons of practice.

The goal of Module 1 was to create suitable conditions for a harmonious adaptation process of pupils to dormitories at vocational training centres. It means that it was necessary to make the first-graders familiar with the dormitory rule and create for them a suitable emotionally and educationally stimulating environment motivating them while eliminating their inappropriate behaviour not only in the dormitory, but also in ordinary life. So-called Operational Objectives were:

${ }^{2}$ Ibidem. 
- For the pupil to learn to solve conflicts and behave assertively (educator to work with work sheets, interactive whiteboard, use situational games, free drama performing, film screening, etc.);

- For the pupil to learn the right attitude towards values such as: aesthetic, moral, economic, scientific, social, health values, etc.;

- For the pupil to learn appropriate behaviour in certain situations.

When using the module, attention was also paid to gradual transition from active occupation to learning activities. The module also included educational and counselling work with parents.

Module 2 concentrated on integration of young disabled people into society. It pointed to non-standard situations in private or working life and found out standards of attitudes towards certain values. It gave pupils "instructions" on how to go on "correctly". Operational Objectives were:

- To be able to accept ethical principles in the communication process;

- To be able to deal with non-standard situations in communication and cooperation in mutual interaction in private or working life;

- For the attendant to be able to work with people, deal with some complicated collisions expected from him/her in practice and by the employer in the field of social issues and family;

- To form standards of attitudes towards values such as: aesthetic, moral, economic, scientific, social values, discipline, health (for the educator to work with worksheets, interactive whiteboard, use situational games, free drama performing, film screening, values, personal value orientation, excursions, field trips, free talks and discussions, discussions with guests - looking for models, various art techniques, theoretical lecture and discussion on gender equality in marriage and love, principles of healthy living, art competition "We Fight against Drugs", etc.).

The main goal of Module 2 application was that a mentally disabled pupil should learn to be orientated in social situations, to solve various problem situations. The module also included educational and counselling work with parents.

The goal of the final - Module 3 - was to prepare pupils of vocational training centres to become active members of society. Thus, the main goal was the value orientation of apprentices in relation to characteristics of individual work types, assessment of future profession suitability for the character of the pupil's personality. Its Operational Objective was to form standards for attitudes towards values (aesthetic, moral, economic, scientific, social values, discipline, health) while also to assure that the acquired knowledge and skills strengthen the pupil's self-competence in orientation in ordinary life. 


\section{Verification of the effectiveness of the programme "Stepping into Life with the Right Values"}

Verification of the effectiveness of the education and training programme "Stepping into Life with the Right Values" was carried out at two selected schools in Slovakia, in the region of Nitra, during the 2015/2016, 2016/2017 and 2017/2018 school years. Participation was voluntary. As mentioned above, its development and subsequent evaluative quasi-experiment involved also cooperation with a psychologist. The pupils of both schools were divided in two groups: the experimental group consisted of pupils at the first school and the control group consisted of pupils at the second school. At the first school (experimental group), educators were attending a new "intensive education and training programme" while working with pupils; at the second school (control group), the traditional method of training was used. The experimental group (EXG) consisted of 25 pupils, 14 boys and 11 girls, and the control group (CG) consisted of 22 pupils, 15 boys and 9 girls. The average age of the respondents was 16.5 years and 16.45 years, respectively.

For the sake of the identification and measurement of the extent of changes, the pupils at both schools fulfilled the value orientation questionnaire designed by Ján Vonkomer (1990). The questionnaire contains 11 various situations, e.g., how to spend free time, who should take care of the state, what we should be grateful to parents for, if you were disposed to excel in some activity which one would you prefer, which human quality you consider as the most important, etc. There are 5 possible answers to each situation, representing 5 value orientations (educational, aesthetic, moral, economic and social). After reading about the situation, answers are assigned an order ( 1 to 5 ) with the answer of the highest importance for the respondent in the first place and the answer of the least importance in the last place. This means that a higher score in a given situation represents a lower preference for the given value orientation. Since there are 5 options (value orientations) for each real situation (or question in the questionnaire), a respondent can obtain a score in the range from 11 to 55 for all 11 answers in total (Note). In this section we state and clarify, in relation to the tables below, that the higher the score obtained by a pupil (in the research sample) in a given value area, the lower its preference. The actual score number is calculated by adding up all points of the alternative answer expressing the specific orientation in question.

Changes in pupils' value orientations were followed up by measuring each pupil's score in individual value orientations (educational, aesthetic, moral, economic and social) during three years, with the pupils fulfilling the same questionnaire each year. 


\section{Research Results}

First, average scores were calculated, obtained in individual value orientations by the pupils in both groups (experimental and control) each year (Table 1).

Table 1. Average scores in value orientations

\begin{tabular}{lcccccc}
\hline & \multicolumn{3}{c}{ EXG } & \multicolumn{3}{c}{ CG } \\
\hline Value orientations & $1^{\text {st }}$ grade & $2^{\text {nd }}$ grade & $3^{\text {rd }}$ grade & $1^{\text {st }}$ grade & $2^{\text {nd }}$ grade & $3^{\text {rd }}$ grade \\
\hline Educational & 37.64 & 36.44 & 27.60 & 39.19 & 34.67 & 39.86 \\
\hline Aesthetic & 38.52 & 37.80 & 30.40 & 38.24 & 35.67 & 37.81 \\
\hline Moral & 37.36 & 37.12 & 33.48 & 37.43 & 34.67 & 35.29 \\
\hline Economic & 30.76 & 24.72 & 25.96 & 23.43 & 29.95 & 27.29 \\
\hline Social & 23.84 & 25.52 & 28.40 & 20.71 & 24.05 & 18.76 \\
\hline
\end{tabular}

The results presented in Table 1 show that the EXG pupils and CG pupils obtained different scores in value orientations in individual grades. We were concerned whether the differences in the score results between the grades were also statistically significant. All the cases tested the zero hypothesis $\mathrm{H}_{0}$, stating that the differences in the pupils' relevant value orientations between the $1^{\text {st }}$ and 3rd grade score results were not statistically significant, against the alternative hypothesis that the differences were statistically significant. Since the assumption of the normal distribution of the observed characters was not substantiated, the Friedman test (Markechová et al., 2011) was used to test the zero hypothesis. It is a non-parametric alternative of the variance analysis of double classification with one observation in each subclass. Calculations were made using the program STATISTICA.

\section{Analysis of change in the experimental group}

For the experimental group of pupils, the questionnaire of value orientations yielded the following results: the test criterion value for $\mathrm{Q}=11.247$ and the significance value $\mathrm{p}=0.004$. Since the calculated value $p<0.01$, the zero hypothesis $\mathrm{H}_{0}$ was rejected at the significance level $\alpha=0.01$, i.e., the Friedman test confirmed that the average scores of the pupils' educational orientations in individual grades were statistically significantly different. To compare differences between individual grades, the Neményi method was used. On the basis of its results, we could state that there were statistically significant differences in the pupils' educational 
orientation between the $1^{\text {st }}$ and 3 rd grades as well as between the $2^{\text {nd }}$ and the 3 rd grades, i.e., the improvement of the 3rd grade pupils' attitude towards education was statistically significant. The situation is illustrated in Figure 1.

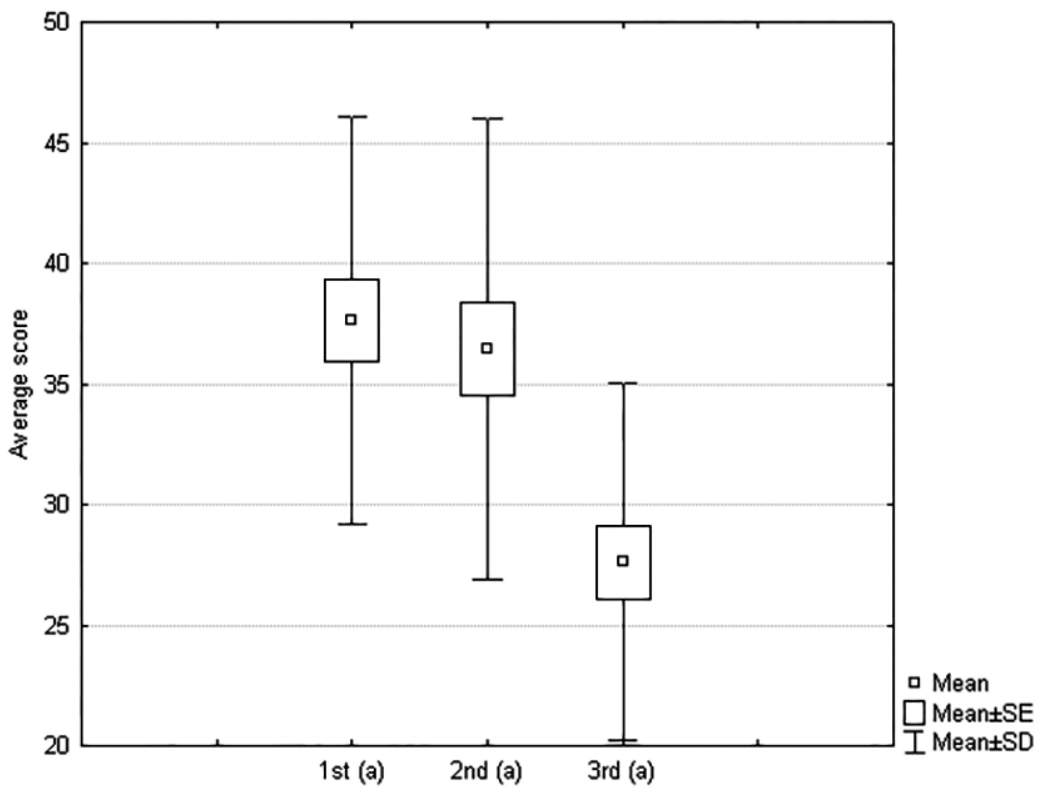

Figure 1. Average scores (EXG pupils' educational orientation) Source: Own design.

Figure 1 shows that although in the $1^{\text {st }}$ and the $2^{\text {nd }}$ grades the pupils had not attributed much importance to education, after application of the education and training programme their attitude towards education changed considerably - it improved considerably in the 3 rd grade.

A similar approach was used to evaluate differences in the next value orientation - the aesthetic orientation. The following values were calculated of the test criterion $\mathrm{Q}=10.129$ and $\mathrm{p}=0.006$. Since in this case the calculated value $p<0.01$, the zero hypothesis $\mathrm{H}_{0}$ was rejected at the significance level $\alpha=0.01$. It means that the observed differences between the average scores of the pupils' aesthetic orientation in individual grades were statistically significant. On the basis of the results obtained by the Neményi method, it could be stated that there were statistically significant differences in the pupils' aesthetic orientation only between the $1^{\text {st }}$ grade 3rd grades It means that the EXG pupils improved their view of aesthetic orientation only after two years of psychological training (Figure 2). 


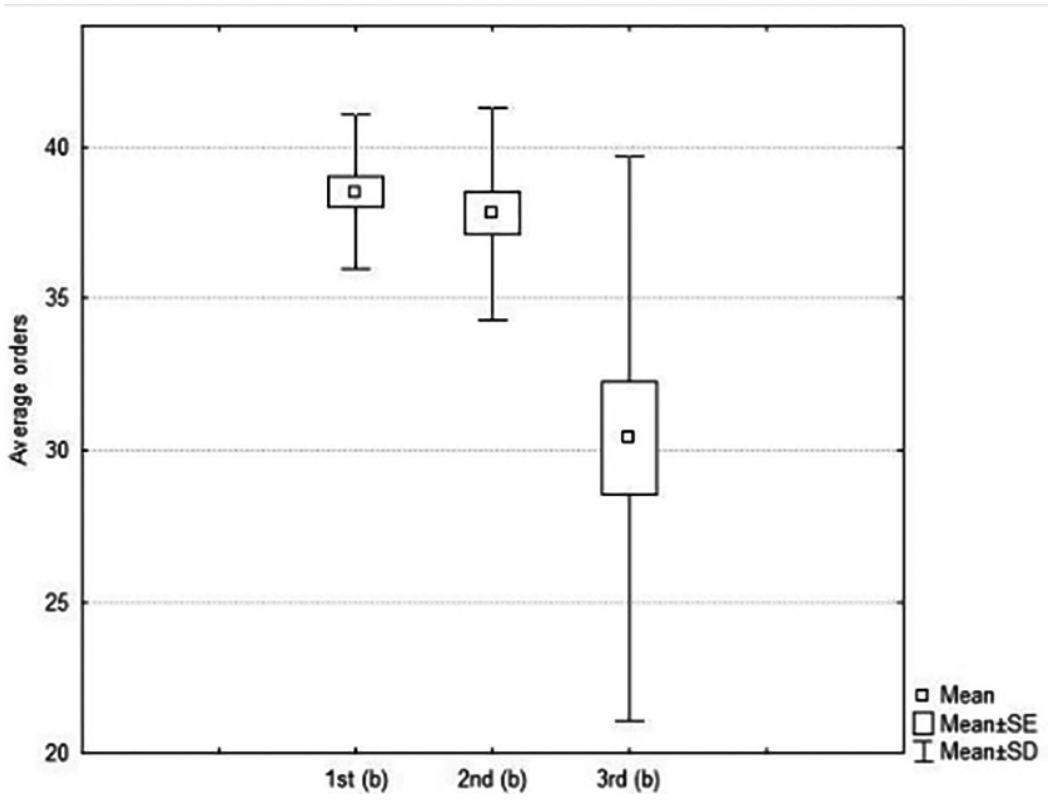

Figure 2. Average scores (EXG pupils' aesthetic orientation) Source: Own design

The Friedman test confirmed that the mean values of the observed character were statistically significantly different both in the moral and the economic orientation, i.e., the pupils' attitudes improved in both orientations statistically significantly. The observed character moral orientation was calculated by the test criterion value $\mathrm{Q}=8.968$ and the probability value $\mathrm{p}=0.012$; and the pupils' economic orientation $\mathrm{Q}=6.842, \mathrm{p}=0.032$. On the basis of the results obtained by the Neményi method, it could be stated that while the pupils' moral orientation changed for the better statistically significantly only in the 3rd grade (Figure 3), the pupils' economic orientation improved statistically significantly immediately after the $1^{\text {st }}$ grade (Figure 4).

The last value orientation - social orientation - was calculated by the test criterion value $\mathrm{Q}=3.305$ and the probability value $\mathrm{p}=0.191$. Since the calculated value $p>0.05$, the zero hypothesis $\mathrm{H}_{0}$ could not be rejected. It means that the observed differences were not statistically significant. The Friedman test confirmed that the pupils in individual grades did not differ in their evaluation of social orientation statistically significantly. 


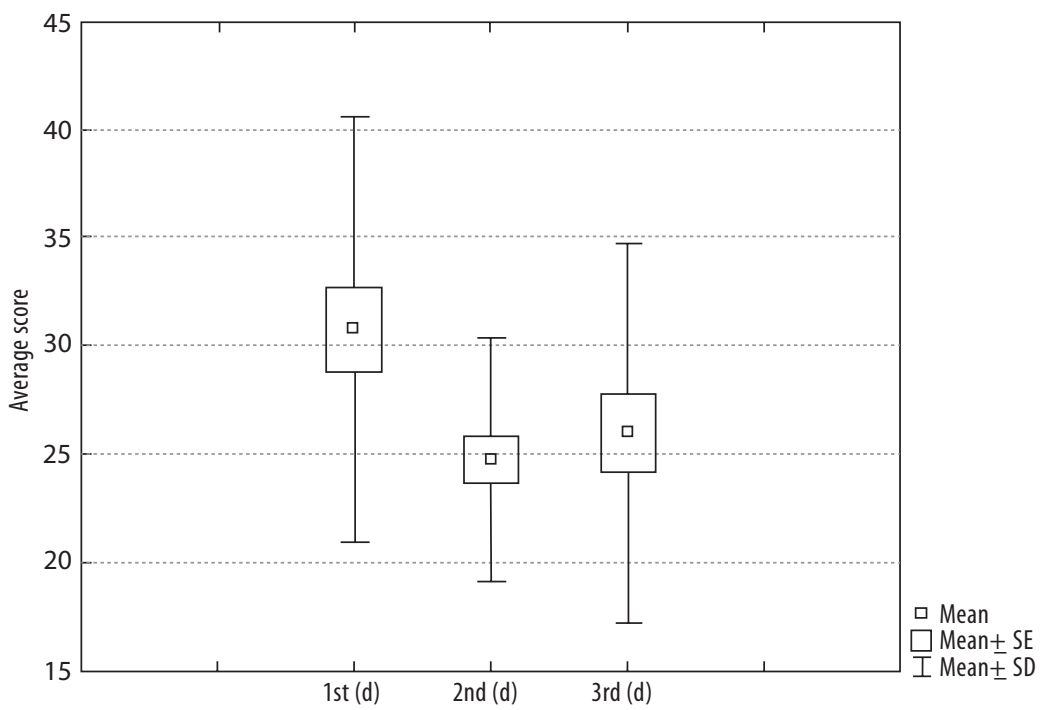

Figure 3. Average scores (EXG pupils' moral orientation)

Source: Own design

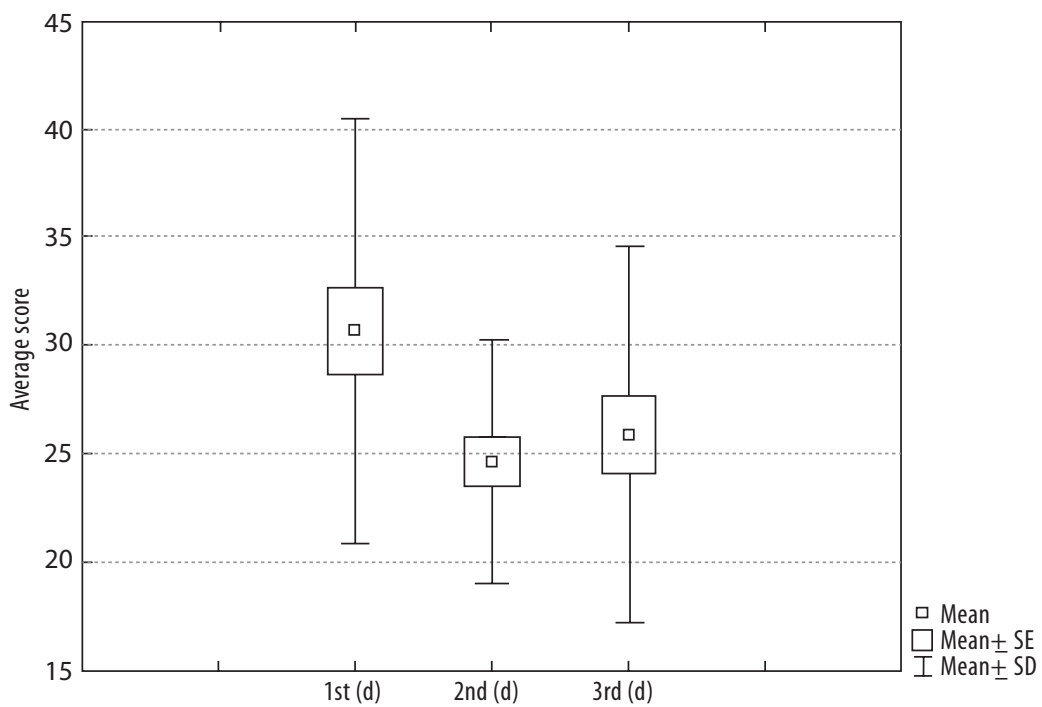

Figure 4. Average scores (EXG pupils' economic orientation) Source: Own design 


\section{Analysis of change in the control group}

The same method was used to analyze the score results of the CG pupils' value orientation, the educational, aesthetic, moral, economic and social orientation. The values of test criteria and probability values are presented in Table 2.

Table 2. Friedman test results (CG)

\begin{tabular}{lcc}
\hline Value orientations & $\boldsymbol{Q}$ & $\boldsymbol{p}$ \\
\hline Educational & 0.105 & 0.948 \\
\hline Aesthetic & 0.138 & 0.933 \\
\hline Moral & 0.400 & 0.818 \\
\hline Economic & 3.963 & 0.138 \\
\hline Social & 0.984 & 0.611 \\
\hline
\end{tabular}

The results presented in Table 2 show that the calculated probability values are higher than 0.05 in all the cases, i.e., the zero hypothesis $\mathrm{H}_{0}$ cannot be rejected even in one case, i.e., there are no statistically significant differences between the pupils in individual grades in the evaluation of any of the orientations. The Friedman test confirms that the pupils in individual grades do not differ statistically significantly in their evaluation of educational, aesthetic, moral and economic orientation, or even social orientation. When looking at Table 1, we can see that there is a slight improvement in the CG pupils' individual value orientations, but the changes over three years are not as considerable as in the EXG pupils.

\section{Conclusions}

On the basis of the performed pedagogical experiment verifying the effectiveness of the education and training programme of our design for mentally disabled adolescents, it can be stated that the effectiveness of the programme for adolescents at vocational training centres was successfully confirmed. When looking at the results obtained from the experiment, we can see that while improvements in individual value orientation results occurred in the experimental group already after the application of Module 1, no considerable changes for the better occurred even in one case in the control group trained traditionally. Improvement in value orientations occurred in the experimental group pupils also when they were applied the other education and training programme modules. Thus, it can be stated that the education and training programme of our design was effective. 
Statistical methods confirmed that the application of the education and training programme increased the educational, aesthetic, economic and moral level as well as thinking in the experimental group pupils statistically significantly - as opposed to the control group pupils, where changes in the above areas were not significant. The results could be interpreted as a certain positive shift in value orientations of mentally disabled adolescents, although the change could have been caused also by some other intervening variables. The results obtained cannot be fully generalized due to the small number of respondents. However, the application of the educational programme in practice indicated that it, too, could be one of the methods to achieve positive changes in mentally disabled adolescents' value orientations. Such changes that facilitate elimination of their inappropriate behaviour, strengthen their social and emotional competence, thus facilitating their best possible integration into life. The fact that the school and dormitory climate improved in particular in the case of the participating in the experiment was apparent. The findings confirm that the programme is suitable for educators' work in school and school facility conditions.

Also, the analysis of the pedagogical research results, as well as cooperation with the school psychologist revealed that at the school where the experiment had been carried out, the climate changed considerably among the pupils in the dormitory, while also relationships improved considerably, not only among the peers but also the adolescents' relationships with their educators.

On the basis of the above facts, it can be stated that application of a suitable intensive education and training programme for mentally disabled adolescents in the dormitory environment of vocational training centres can eliminate inappropriate behaviour of pupils in the dormitory, strengthen their social and emotional competence, thereby facilitating their best possible integration into life.

\section{References}

Aluja, A., Garcia, F. (2004). Relationships between Big Five Personality Factors and Values. Social Behavior and Personality. 2004. č. 32, s. 619-629.

Cronbach, L.J., Meehl, P.E. (1955). Construct validity in psychological tests. Psychological Bulletin, 52, 281-302. doi: 10.1037/h0040957.

Johnson, G.M. (2010). Internet use and child development. The techno-microsystem. Australian Journal of Educational and Developmental Psychology, 10, 32-43.

Herráe, A. (2006). Biomolecules in the Computer. Biochemistry\& Molecular Biology Education, 34 (4), 255-261.

Hofstede, G. (2001). Culture's Consequences. Comparing Values, Behaviors, Institutions, and Organizations Across Nations (2 ${ }^{\text {nd }}$ Edition). 2001. Thousand Oaks: Sage, 2001. 
Markechová, D., Stehlíková, B., Tirpáková, A. (2011). Štatistické metódy a ich aplikácie. Nitra, UKF, 534 s., (Markechova, D., Stehlikova, B., Tirpakova, A. (2011). Statistical methods and their applications. Nitra, UKF, 534 s.).

Miliacca, C., Gagliardi, G., Pescatori, M. (2010). The 'Draw the Family Test' in the preoperative assessment of patients with anorectal diseases and psychological distress: a prospective controlled study. Colorectal Diseace, 12, 792-798. doi.org/10.1111/j.14631318.2009.01985.x.

Novák, M., Langerová, P. (2006). Raising effectiveness in teaching mathematics in non-English speaking countries: an electronic bilingual dictionary of mathematical terminology. In: Proceedings of 3 rd International Conference on the Teaching of Mathematics at the Undergraduate Level. Istanbul: TMD (Turkish Mathematical Society), 2006. [CD-ROM].

Posner, M. (2004). Neural systems and individual differences. TC Record. Retrieved 3/08/2005, from http://www.tcrecord.org/PrintContent.asp?ContentID $=11663$

Prunner, P. (2002). Výzkum hodnot. Plzeň: Euroverlag. 2002. (Prunner, P. (2002). Value research. Plzen: Euroverlag. 2002.

Roccas, S., Sagi, L., Schwartz, S.H., Knafo, A.(2002). The Big Five Personality Factors and Personal Values. Personality and Social Psychology Bulletin. 2002. č. 28, s. 789-801.

Rosenzweig, S. (1981) Adolescent Form Supplement to the Basic Manual of the Rosenzweig Picture-Frustration (P-F) Study. 1981.St. Louis: Rana House.

Thurstone, L.L. (1959). The measurement of attitude: a psycho-social method and some experiments. Chicago: University of Chicago.

Vaitkevičius, J. (1995). Socialine spedagogikos pagrindai. Vilnius: Egalda.

Vonkomer, J. (1990).Psychologická diagnostika v škole. Psychodiagnostické a didaktické testy. Bratislava: Psychodiagnostika, 1990. (Vonkomer, J. (1990). Psychological diagnostics at school. Psychodiagnostic and didactic tests. Bratislava 1990). 